\title{
ARQUITECTURAS DE LAS CONTINGENCIAS
}

\author{
Emilio Farruggia
}




\section{EMILIO FARRUGGIA}

Doctor (Cand.) en Arquitectura y Arquitecto, Universidad Nacional de Rosario (Argentina). Licenciado en Educacional Tecnológica. Universidad de Salamanca (España). Ejercicio profesional Independiente. Docente, educación secundaria, terciaria y universitaria. Director de la Carrera de Arquitectura, Sede Regional Rosario, Universidad Abierta Interamericana (Argentina). Ex presidente, Colegio de Arquitectos de la Provincia de Santa Fe y del Distrito dos Rosario.

FECHA DE RECEPCIÓN: 15 de agosto de 2018 FECHA DE ACEPTACIÓN: 7 de noviembre de 2018.

REGISTRO BIBLIOGRÁFICO: Farrugia, E. (2018). Arquitecturas de las contingencias. Anales de Investigación en Arquitectura, 8, 43-64. 


\section{RESUMEN}

No alcanza con ser parte del presente para acreditar las cualidades que caracterizan este tiempo, al menos en sus versiones más relevantes y transformadoras. La prueba de ello, es que muchos proyectistas de Arquitectura, evitan las tensiones actuales y actúan anclados a permanencias e invariables que sobreviven gracias a la repetición, la regularidad y discreción de sus ofertas. En este escrito se habrá evidenciado nuestra interpretación de ciertas arquitecturas contemporáneas, operadas por arquitectos sudamericanos dispersos por los ciudades de este continente, interesados en salir de la especulación visual y sostener expectativas en la recepción conceptual y sensorial de sus obras, menos aplicados en fijar principios y definiciones y más ocupados en avanzar actuaciones y argumentos.

Por lo tanto, para moverse hacia lo contemporáneo es necesario el movimiento, o el desplazamiento hacia otros lugares, topografías las Ilama Ignasí de Sola Morales, es decir, hacia otros ámbitos alternativos de procedimientos teóricos-prácticos. En este escrito trataremos de aproximar el proyecto de algunas de las arquitecturas actuales de Sudamérica caracterizadas por sus cualidades materiales, objeto de nuestras indagaciones, a las prácticas artísticas actuales. Se trata de múltiples actuaciones simultáneas que a modo de mosaico emergen en el suelo sudamericano y, como acontecimientos, sacuden la regularidad de las producciones mayormente discreta de esta disciplina.

Palabras clave: Desplazamientos - acontecimiento - artístico - expansión.

\section{ABSTRACT}

It is not enough to be part of the present to prove the qualities that characterize this time, at least in its most relevant and transformative versions. The proof of this is that many architects of Architecture, avoid current tensions and act anchored to permanence and invariables that survive thanks to the repetition, regularity and discretion of their offers. In this paper we have demonstrated our interpretation of certain contemporary architectures, operated by South American architects scattered throughout the cities of this continent, interested in getting out of visual speculation and holding expectations in the conceptual and sensory reception of their works, less applied in setting principles and definitions and more occupied in advancing actions and arguments.

Therefore, to move towards the contemporary movement is necessary, or the displacement towards other places, topographies called the Ignasi de Sola Morales, that is, towards other alternative fields of theoreticalpractical procedures. In this paper we will try to approximate the project of some of the current architectures of South America characterized by their material qualities, object of our inquiries, to current artistic practices. These are multiple simultaneous actions that, like a mosaic, emerge in the South American soil and, as events, shake the regularity of the mostly discrete productions of this discipline.

Key words: Displacement - event - artisitic - expansion. 
En los últimos años se ha puesto de relieve el trabajo de un buen número arquitectos sudamericanos residentes en las ciudades de este continente, a los que premios internacionales, difusión en publicaciones y valoraciones críticas, los han proyectado sobre la escena mundial de las producciones arquitectónicas. Solano Benítez (Figuras 1 y 2)y Javier Corbalán (Figura 12) en Paraguay, Rafael Iglesia (Figura 6), Marcelo Villafañe (Figura 7), Nicolás Campodónico (Figura 3), de Rosario, Argentina, José Saez Vaquero (Figura 4) y estudio Al Borde (Figura 5) de Quito, Ecuador, Smiljan Radic (Figura 8 y 9), German del Sol, y Alejandro Aravena (Figura 11)de Chile, Felipe Mesa (Figura 10) y Giancarlo Massanti, en Colombia, entre otros, se han convertido en realizadores destacados de la arquitectura de estas regiones y referentes principales del nuevo contexto cultural creado en buena medida por ellos.

El trabajo que exhiben es amplio y diverso y responde a los alcances de una demanda mayormente privada, local y cercana, procurando atender aplicadamente todos los aspectos de esta disciplina. Sin embargo nuestra percepción focaliza en unos aspectos particulares y recorta lo que nos parece uno de los tramos más relevantes y causales de estas obras: un singular interés por involucrar en su labor una fuerte incidencia de la materia y la técnica en los procesos de ideación. Variaciones en la disposición de los materiales, experimentaciones técnicas y constructivas, la interrogación estructural, focalizan la atención formal y plástica de los arquitectos que en esta instancia concitan nuestro interés. No es igual en todos los casos, en algunos hay una manifiesta voluntad por experimentar de modo directo y personal con las materiales y las técnicas, en otros se percibe que el ingenio está puesto de relieve para usar materiales en forma no convencional, sea como alternativa estructural, constructiva, o económica. La utilización de materiales convencionales y cotidianos como por ej. la madera, el ladrillo, el hormigón, entran en relación dialógica con la idea. El concepto arquitectónico emerge de este diálogo entre materia, técnica y forma.

Las operaciones proyectuales de estos arquitectos incorporan otras opciones que alteran los procedimientos ya paradigmáticos en esta disciplina por los cuales el diseño queda separado de la construcción. Como se dijo anteriormente en estas alternativas la materia se presenta como oportunidad de la invención y adquiere un rol sustantivo, por lo tanto, el trabajo de investigación iniciado indaga esos procesos proyectuales y las propias ideaciones constructivas que dan lugar a estas obras en el contexto de la ampliación de las prácticas artísticas que caracteriza estado actual de la cultura arquitectónica.

\section{LA CONDICION CONTEMPORANEA}

Ubicamos la situación temporal de nuestras indagaciones en lo contemporáneo, esto es, un 
entorno que no se describe sólo por los años en lo que suceden los hechos que indagamos sino, además, por los sentidos que distinguen estas fechas de otras anteriores. Gianni Vattimo en la década de los ochenta anunció que la modernidad había concluido, al menos en varias de sus características más definitorias. En su opinión, concluyó la época "en que ser moderno se convierte en un valor determinante" (Vattimo, p.73, 1989), lo que supone que se modificaron no solo formas de pensar las cosas, sino por sobre todo, se presentaron otras prácticas sociales que identifican, en los mismos ámbitos, otros modos de actuación.

Vattimo nos propone reflexionar sobre dos situaciones que alteraron el estado de cosas en el último cuarto del siglo XX, en su libro "La sociedad transparente" dice:

Han ocurrido muchas cosas y muy diferentes: Ios llamados pueblos primitivos, colonizados por los europeos en nombre del recto derecho de la civilización "superior" y más evolucionada, se han rebelado, volviendo problemática, una historia unitaria centralizada. (...)Junto con el fin del imperialismo y el colonialismo, otro gran factor ha venido a resultar determinante para la disolución de la idea de historia y para el fin de la modernidad: se trata del advenimiento de la sociedad de la comunicación.

(Vattimo, 1989, p. 77).

Desde nuestro punto de vista, estas dos circunstancias son principales para nuestro interés y aprecio por varias de las arquitecturas que suceden en Sudamérica. La disolución de ese orden imperialista, no representó únicamente una condición política de la relación de poder entre los países, además conlleva la configuración de otro orden cultural, en el que las manifestaciones artísticas tampoco responden a una matriz vertical con centro en Europa o EEUU. La intensa circulación de información sobre hechos, imágenes, argumentos, ha creado un estado de cosas paralelo y simultaneo, sincrónico, en que cada vez más se debilita la percepción del tiempo como historia, unitario y sucesivo, diacrónico.

Por lo tanto aquella posmodernidad anunciada y descripta por Gianni Vattimo hoy la comprendemos como un proceso globalizador que muestra el desmembramiento de los centros de poder y las polaridades de otros tiempos claramente modernos, y en su despliegue, no se reconocen posiciones dominantes, liderazgos permanentes, aunque sí fuertes conflictos, diferencias, alianzas regionales y conveniencias. Es evidente además, que nada de ello ha sucedido por fuera de los desarrollos tecnológicos tanto en el ámbito de la producción como de las comunicaciones, sin embargo se trata de un conjunto ilimitado de impulsos que lejos de disminuir las disparidades sociales, ha acentuado la desigualdad y la distancia entre ricos y pobres.

Reconocer los valores de las producciones sudamericanas y alinear sus méritos en el 
contexto mundial era impensado no muchos años atrás y exponen los sucesos de un proceso comunicacional más amplio y global en el que han proliferado y dispersado los ámbitos de producción cultural por todo el planeta, incorporando y combinando un $\sin$ fin de actividades de diversa naturaleza.

Los arquitectos que indagamos, Solano Benítez, Smiljan Radic, Rafael Iglesia, Alejandro Aravena, Al borde, Marcelo Villafañe, Nicolás Campodónico y las arquitecturas producidas por ellos nos lo presentamos como un mosaico, que los vincula el suelo sudamericano, e intencionadamente cruzamos sus trayectorias en la cuestión de la materialidad, en tanto nos admira el tratamiento diferenciado y singular que dan a la concreción material de la obra, aun siendo trayectorias que se inician en distintas regiones, se procesan y dan resultados estéticos distintos.

Segùn Ignasí de Solá Morales la arquitectura ya no debe ser interpretada como un árbol, desde una raiz, un tronco, ramas y hojas. En su lugar, nos detenemos en la idea de mosaico, pensando en aquel material compuesto por trozos pétreos de distintos tamaño y forma, dispersos en su superficie expuesta, sin contacto entre ellos y unidos por la mezcla cementicia. La analogía nos parece oportuna si vemos la emergencia reciente, en los últimos 25 años, de ese número significativo y elocuente de proyectistas sudamericanos destacados, dispersos entre los países del continente, sin huella de relaciones previas entre ellos, ni involucrados en un programa común, aunque unidos por el suelo sudamericano y el espesor de un tiempo opacado por la intensa carga de la información simultánea que nos alcanza. Esta lectura opacada del tiempo la referenciamos en Gianni Vattimo, quien lo explica de la siguiente manera:

Lo que intento sostener es: a) en el nacimiento de una sociedad posmoderna los mass media desempeñan un papel importante; b) que estos caracterizan tal sociedad no como una sociedad más "transparente", más consciente de si misma, más "iluminada", sino como una sociedad más compleja, caótica incluso; y finalmente c) que precisamente en este caos relativo residen nuestras esperanzas de emancipación.

(Vattimo, 1989, p. 17)

Cuandosituarnoslaarquitectura contemporánea en las condiciones de la posmodernidad no lo hacemos siguiendo una lógica binaria, negativa, antagónica, sino mirando estas diferencias irreversibles, positivamente, como alteraciones que anuncian la emergencia de ricos valores para la arquitectura y sus procedimientos de producción. Durante el tramo del ascenso moderno en Sudamérica, la cultura de la especialidad convocaba a incorporase a un modo racional de proceder, necesariamente fundamentado, y a trabar vínculos a través del dominio del código de un lenguaje moderno universalizado, el tiempo presente 
muestra la persistencia de su contrario, esto es la disolución de la uniformidad de procedimientos, la fuga según múltiples huellas estéticas y experiencias críticas. Es decir, estos arquitectos no anhelan ser modernos y, en este sentido, seguimos la huella de una versión posestructural del procedimiento proyectual en el que no se siguen "procesos deductivos cuyos movimientos iniciales determinan la suerte de todos los pasos sucesivos" (Gianni Vattimo, 1983, p.19), esto es, movimientos guiados por principios preconstituidos, tenidos como verdaderos, probados y seguros relacionados con la funcionalidad, la estética y la materialidad. En su lugar, estamos frente a procedimientos conjeturales, en los que los argumentos, los recursos materiales y formales inducen procesos imaginarios que no aseguran la certeza del resultado y siguen las oportunidades que se derivan de la contingencia.

Según esto, a nuestro criterio, se aplica más adecuadamente la noción de acontecimiento que de tradición. En el acontecer contemporáneo,con los arquitectos sudamericanos indagados y con la intensa circulación de información, vemos irrumpir proyectos y obras en simultáneo y distantes, que iluminan los temas de la arquitectura sin referentes cercanos, según iniciativas, argumentos proyectuales y opciones materiales disimiles. Por ello esta noción de acontecimiento se deduce mejor de la percepción empírica que de una lógica abstracta. La noción de acontecimiento la encontramos expuesta con amplitud por Ignasí de Solá Morales en su libro "Diferencias. Topografías de la Arquitectura contemporánea". En este texto el autor utiliza el concepto de "arte intempestivo" y luego introduce el de "arquitectura intempestiva", para explicar su irrupción del acontecimiento en arquitectura. A partir de reconocer como condición contemporánea la multiplicidad ilimitada de posiciones, el ejercicio de la arquitectura se acompaña de construcciones provisionales que argumentan, más que fundamentan, los proyectos. Sucede un pasaje de la idea (metafísica e invariable) a la experiencia, por lo que la obra queda vinculada, al momento, a las contingencias, y a "la proposición levantada en el lugar", dice Ignasí de Solá Morales.

La noción de acontecimiento que suscribimos parte de aceptar y promover la heterogeneidad de la situación actual y confronta con aquel descreimiento de la corporación y con las insuficiencias críticas del aparato académico. Entendemos descreídas aquellas concepciones discretas y ordinarias, solo ocupadas en la utilidad, la funcionalidad, y las estéticas más seguras, aquellas de la representación de lo mismo. La heterogeneidad es el relieve de la superficie contemporánea en la que se observan la expansión de sus procedimientos y sus cualidades específicas atravesando los criterios modernos, ya tardíos, de construir el problema y buscar sus soluciones. Estas arquitecturas sudamericanas son apenas unas 
de las muchas modalidades en las que esta especialidad cultural se ha dispersado a lo largo del globo.

\section{EL AMBITO ARTISTICO DEL PROYECTO}

En el ámbito extenso e ilimitado del arte contemporáneo, el que corre en paralelo a la globalización, es el tiempo en el que la arquitectura recupera sus vetas artísticas expandiendo sus expectaativas más allá de los límites de los esquemas modernos, ampliando sus propios enunciados mediante los conocimientos de otras especialidades e incorporando positivamente argumentos de otras medios artísticas. El surgimiento de estas corrientes no es reciente y siguen la evolución de las modificaciones que tuvieron lugar en el último cuarto del siglo $X X$, y sobre los que Andreas Huyssen en el año 1986 escribió un texto significativo llamado "Después de la gran división". En él encontramos referencias como la siguiente:

Aunque la desmedida publicidad acerca del posmodernismo en la arquitectura y en las artes sacó el fenómeno a la luz pública, oscureció al mismo tiempo su historia larga y compleja. Mi análisis se basará en gran medida en lo que se advierte en un nivel como la última moda, producto publicitario y espectáculo vacío y falso, forma parte de la lenta emergencia de una transformación cultural de las sociedades occidentales; (Huyssen,1986, p. 311)
Si nos remitimos a los cursos de formación de estos profesionales vemos que con diferencias de pocos años, en su mayoría atravesaron la década del '80, cuando la tormenta posmodernista sacudió particularmente a la Arquitectura y a la tranquilidad descreída del estilo internacional. Si bien ese momento y sus realizaciones han sido olvidados, no podemos soslayar el altísimo impacto que tuvo sobre los arquitectos y sus proyectos, cuando de pronto, se habilitaba la mirada sobre el pasado de la arquitectura al que se lo tomó como archivo disponible para nuevas proyecciones estéticas.

La arquitectura encontró en esta novedad ecléctica, globalizada, la fuga al vacío alcanzado por el estilo internacional y, luego de ello, ya nada volvió a su lugar. Como lo dice Huyssen fue una "tentativa inútil... definir lo posmoderno meramente en términos de estilo". (Huyssen, 1986, p.9). Es significativo este momento, porque más allá del fracaso de varios intentos teóricos y estéticos, muy difundidos, no hay duda que señala las limitaciones y los cuestionamientos a lo moderno como ámbito de pensamiento y construcción de la realidad. Para Huyssen, se produjo lo siguiente

"Por un lado la emergencia de una cultura cargada de eclecticismo, un posmodernismo afirmativo que había abandonado toda pretensión de crítica, transgresión, o negación, y por otro la aparición de un posmodernismo alternativo en el cual la resistencia, la crítica y la negación del 
estatus quo fueron definidos en términos no modernistas y no vanguardistas, términos que acompañan la evolución política de la cultura contemporánea más eficazmente que las viejas teorías del modernismo". (Huyssen, 1986, p.324).

Precisamente aquello que el autor advierte y teoriza en los '80 es lo que verificamos en varios proyectistas de la actualidad. Este cambio de las sensibilidades, formaciones discursivas y proposiciones se originan como desplazamiento o distanciamiento de lo existente, aquella cultura moderna envejecida, autónoma y vaciada de contenidos contextuales y culturales. Terry Smith en línea con el desmembramiento de las dicotomías anunciado tiempo antes por Andreas Huyssen, advierte las diferencias, aunque ya no antagónicas, o destructivas:

Como he señalado, el concepto de lo contemporáneo, lejos de ser singular y simple - un sustituto neutro de lo "moderno"-significa múltiples modos de ser con, en y fuera del tiempo, por separado y a la vez, con otros y $\sin$ ello. Estos modos, desde ya, siempre estuvieron allí. La diferencia reside en que en nuestros días, las multiplicidades de forma de ser contemporáneo predomina sobre los distintos poderes generativos y destructivos. (T. Smith,2012, p.21)

Es posible reconocer las situaciones que acuñadas en los tiempos modernos ya no suceden. Una que se destaca y podemos comprobar en el ámbito de la Arquitectura, es que las obras no reconocen corrientes o estilos estéticos a los que representar. Smith conjetura que en este tiempo es poco probable que el arte de lugar a un nuevo paradigma predominante, y con ello a estilos que dominen la escena artística.

En lo concerniente a las artes visuales, resulta evidente que, desde los años setenta, ninguna tendencia logró una predominancia similar, capaz de posicionarla como firme candidato a ser el estilo dominante de la época."(2012. P 303). Y, agrega “existe la impresión de que el arte contemporáneo tiene una diseminación local, regional, lateral y transversal cada vez mayor, eludiendo la integración vertical impuesta por el mercado y el sistema publicitario del arte internacional. (Smith, 2012, p. 312).

Cesar Aira en su pequeño pero ilustrativo libro "Sobre el arte contemporáneo" participa de esta lectura, pero lo hace en términos de nombre:

En la década de 1960 hubo una aceleración explosiva; los nombres, y lo que designaban los nombres, proliferaron: pop, op, minimalismo, conceptual, land art, fotorrealismo, arte povera y cien más. Como toda explosión en forma, dejó la tierra arrasada; en adelante ya no hubo nombres; los pocos que se propusieron después, como pattern painting, o bad painting, o Die Neu Wilden (los nuevos fauves) (todos en los setenta), o la transvarguadia, fueron fugaces 
o limitados. Se había clausurado el carnaval de Ios nombres...(Aira, 2013, p.32).

Es oportuno aclarar que la estética contemporánea no delimita los campos de actuación a ciertas áreas. Por el contrario se extiende por igual, casi de forma líquida, al diseño de una máquina agrícola, la grifería, la indumentaria, la informática o las producciones audiovisuales. Es en ese contexto contemporáneo cuando los procedimientos artísticos encuentran su ampliación y desarrollo, y lo útil, necesita imprescindiblemente de conceptos de belleza que lo instalen y diferencien de la infinita oferta de productos que circulan tanto de modo tangible como virtual. La arquitectura se desenvuelve en las condiciones de este tiempo y la proliferación de las actividades artísticas la involucran y es más, necesita de sus realizaciones para que el mundo alcance las evidencias de su representación. Terry Smith aporta lo siguiente:

Hoy el arte está determinado de una forma más profunda por su situación dentro de la contemporaneidad. (...)La contemporaneidad se manifiesta no sólo en la inaudita proliferación de arte, o en sus variaciones aparentemente infinitas, sino ante todo en la emergencia y la confrontación de modos muy distintos de hacer arte y de emplearlo para comunicarse con los demás.

(T.Smith, 2012, p.21).
César Aira destaca dos situaciones principales para la construcción de un horizonte artístico en una actividad cultural y productiva: por un lado crear "valores nuevos" y, por otro, y vinculado a ello, alejarse "de los parámetros de calidad ya fijados", o lo que es lo mismo, alejarse de ciertas tradiciones dominantes. Las obras de los proyectistas mencionados procuran indagar y revisar los tópicos que inician y movilizan los proyectos y si bien, como decimos, se percibe una fuerte impresión en las cuestiones materiales, los entornos conceptuales en los que ello se produce también son sometidos a interrogaciones decisivas. Vemos por un lado, las invocaciones a metáforas, memorias, supuestos lógicos, atmosferas, recursos materiales disponibles, contextos, ambientes, y sobre todo, el alejamiento de los patrones funcionales y formales más habituales que acompañan los desarrollos proyectuales corrientes. En esta interrelación entre lo subjetivo y lo material, puede verificarse alteraciones significativas en la definición de los espacios, los recorridos, las relaciones entre exterior e interior, los esquemas estructurales, las envolventes.

\section{OBRAS Y PROYECTISTAS}

En el período en el que nos ha tocado atravesar esta profesión, las palabras forma, estética, artístico, belleza, subjetivo... fueron recurrentemente evitadas y hasta reprimidas en las especulaciones proyectuales $y$, por supuesto, en el discurso académico. Nuestro 
reconocimiento de las obras que hoy nos ha interesado investigar resuena en aquel mismo ámbito artístico que los restos de esta cultura tardo moderna, aún activa, se ocupa de soslayar. Su tratamiento particularmente imaginativo de las materialidades, es revelador de compromisos críticos y contextuales que recuperan para la Arquitectura la proyección de valores propios de las actividades artísticas, particularmente próximas al estado actual de las controversias contemporáneas.

La nómina de los proyectistas y obras que distinguimos es sólo una parte de la producción reciente dispersa por Sudamérica, la que la reconocemos más extensa y tan rica como la que aquí se presenta. A la vez, esta selección no es un perímetro cerrado, en tanto otros proyectistas y otras obras, total o parcialmente, suman nuevos casos a esta interpretación. Buscamos entre aquellos colegas que amplían y crean valor tanto en los procedimientos proyectuales como en las formalizaciones obtenidas. sin embargo, nos interesa verificar ese doble movimiento que, por un la dado, promueve la ampliación de los procesos que hibridan conceptos, materiales, técnicas y formalizaciones, y al mismo tiempo, se afana por escapar de los trayectos detenidos en la resolución visual.

Los proyectistas y obras que a continuación incluimos son algunos ejemplos de un listado mayor del que también forman parte José Sáez Vaquero, Javier Corvalan, Marcelo Villafañe,
Daniel Bonilla, Nicolas Campodónico, Angelo Bucci, etc.

Solano Benítez en una entrevista reciente publicada por la revista “30-60. Cuaderno latinoamericano de Arquitectura", es coincidente con la opinión de Aira:

"Cuando empezamos nosotros sabíamos construir bien, pero lo que sabíamos costaba 15.000 o 20.000 dólares. Necesitábamos construir la misma cantidad de espacio pero teníamos 5000 dólares. Todo lo que sabíamos no nos servía. Entonces teníamos que inventar, teníamos que empezar a mirar la materia de una manera distinta, que más allá de la importancia de cómo se pone el ladrillo, es la actitud de poder decirle a una disciplina que está ultra entrenada en la reproducción y en el bien hacer que en realidad bien haciendo y de la mejor manera no alcanza..."

(Colección 30-60.Cuaderno latinoamericano de Arquitectura, 45, p179).

En el año 2012 visitamos una obra de Solano Benitez en Patiño, un poblado cercano a la ciudad de Asunción del Paraguay a orillas del lago Ipacaraí y, como toda la región ya tropical en este continente, presenta un vegetación profusa, tierra colorada, superficie mayormente llana y temperaturas elevadas durante todo el año. Visitamos la casa que Solano Benítez construía para un joyero suizo y su familia. 


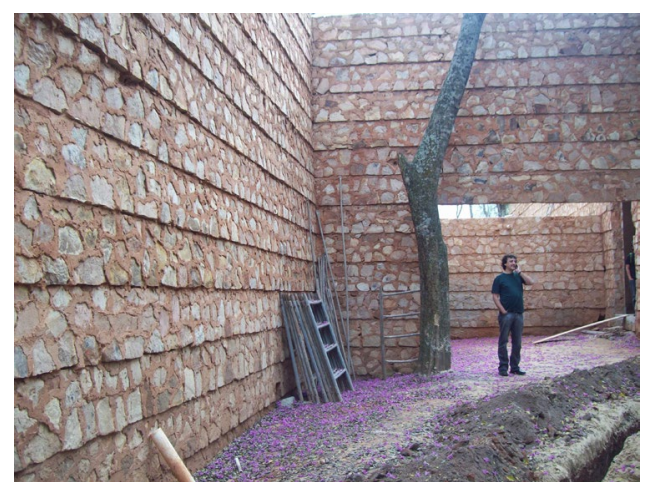

Figura 01.

Casa en Ipacaraí. Paraguay Arqs. Gabinete de Arquitectura. Año 2011. Fotografía Emilio Farruggia.

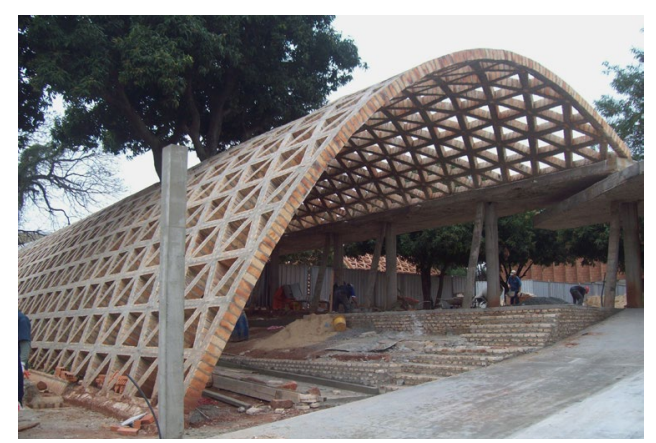

Figura 02.

Centro rehabilitación infantil Teleton. Asunción del Paraguay. Arqs. Gabinete de Arquitectura. 2010. Fotografía Emilio Farruggia
Rápidamente reparamos en la altura de los muros, su espesor y su textura 'cruda'.. La impresión no era sólo estar frente a una pared sino frente a un material. La creación de este material y la técnica de construcción estaba dirigida a mejorar los tiempos y los costos de la obra, y a percibir una cualidad fuertemente matérica antes que formal. Este mampuesto con una cara de cascote al exterior construido mediante el uso de tutores se completa en su cara interior mediante una pieza prefabricada con los mismos materiales más un agregado de cemento, que hace de encofrado y permite el llenado posterior con hormigón de cascote. estas paredes se levantaban sobre vigas de hormigon, separadas del piso y todo el conjunto alcanza un espesor atento a las alturas requeridas y se justifica en los tiempos de construcción y la utilización del material del lugar: la tierra colorada, cuya viscosidad reemplaza el rol aglutinante de la cal. .

En el año 2008 el arquitecto Rafael Iglesia proyectay construye una Clinica de Reproduccion Asistida en la ciudad de Rosario. La obra era la reforma de una casa de dos plantas existente y para ello el proyectista decide ocultar la fachada de la vivienda mediante un plano de chapa plana cromada que refleja y "reproduce" las imágenes que le son próximas. Al describir el frente de chapa cromada y reflejante, con el que se construye la fachada de las dos plantas de la Clínica comenta Iglesia: 
"Esto que no se sabe bien qué cosa es, esconde detrás una clínica de reproducción asistida. Reproducción. Donde tiene más valor la idea que el contenido, el significado como principio constructivo. Nada hace suponer que es habitable, no hay puertas, ni ventanas, cornisas, todo eso que diferencia a la Arquitectura. Esta fachada no tiene memoria, no recuerda estilo, un modo de hacer, una época o nos comenta una utilidad. El ingreso surge cuando un módulo del frente se empuja hacia atrás para abrir un vano que permite entrar o salir. Es decir el verbo, entrar, salir, cerrar, abrir y no el sustantivo puerta".

(Revista Gua-y, 2012, UAI)).

En el año 2010 el arquitecto chileno Smiljan Radic proyecta y construye el restaurante "El mestizo", al que visitamos en este año 2018 , y donde una gruesa pérgola de hormigón visto, crudo, pintado de negro conforma el espacio intermedio que da continuidad al parque y sus lagunas en los límites propios del restaurant y al que Radic llama "un interior en el exterior". Sin embargo, para conseguir el ambiente, o la atmósfera que se propone en el proyecto, Smiljan Radic recurre no sólo al hormigón crudo sino también a grandes piezas de granitos de varias toneladas que puntualmente sostienen la pérgola. Explica Smiljan Radic:

"Estas piedras macizas son la estructura del edificio, son el soporte no sólo de sus cargas propias sino también de su imaginario, de su organización interna, y de la memoria que se

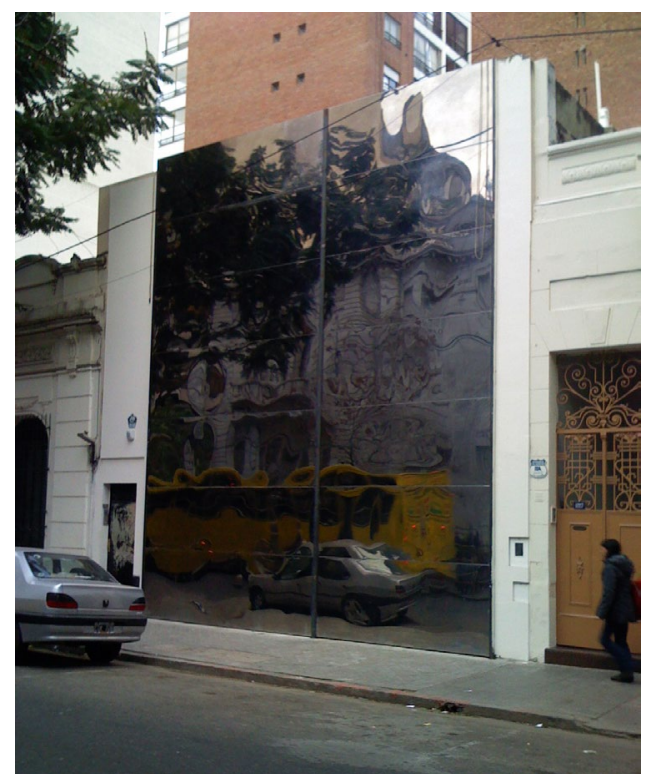

Figura 03.

Clínica de Reproducción asistida. Arq. Rafael Iglesia. Rosario. Argentina. 2004. Fotografía Gustavo Farías. 


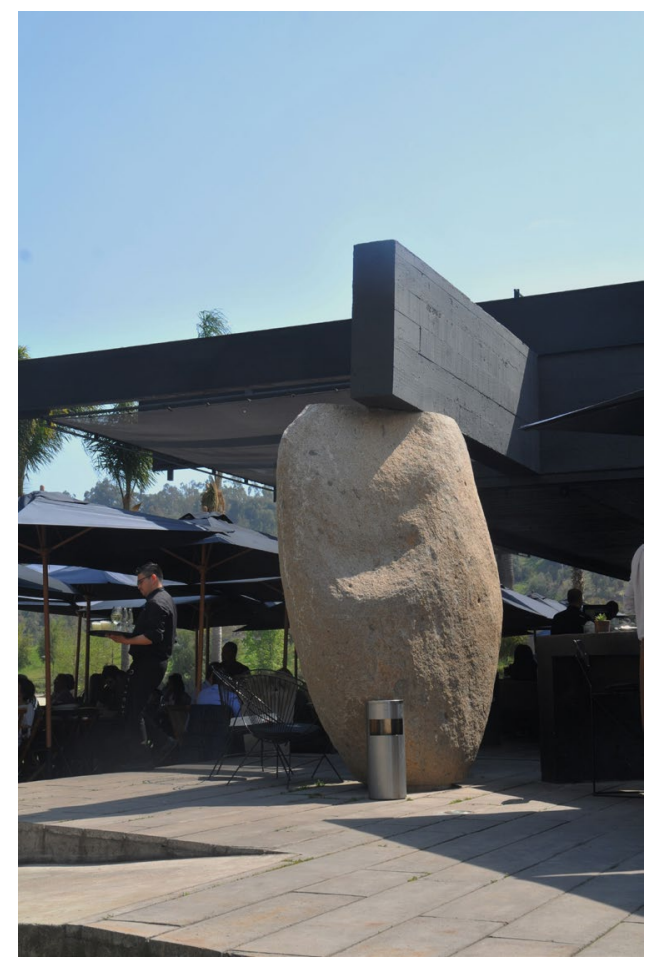

Figura 04.

Clínica de Reproducción asistida. Arq. Rafael Iglesia. Rosario. Argentina. 2004. Fotografía Gustavo Farías. Autorizada. tiene de él. El usuario asocia los granitos a la estructura formal del parque, a la intemperie, aunque su verdadera labor sea sostener una cubierta suspendida sobre uno de sus rincones".

(Entrevista por José Castillo. Revista Bomb, 106.)

Así dicho, el proyecto del restaurant participando de un parque y sus lagunas no está orientado a significar una forma edilicia que identifica un programa; en su lugar se interesa por construir un ambiente, siendo el ambiente la interpretación más específica del espacio con la que este pierde abstracción y se vuelve cosa física, se vuelve un proyecto de la intemperie. Las enormes piedras de granito y el hormigón visto construyen el significado, se ocupan de la dimensión subjetiva, el imaginario, que trasciende la finalidad.

En el año 2007 el estudio Al borde, constituido por los arqs. David Barragan y Pascual Gongotena proyectan y construyen una casa en las faldas del volcon Ilaló, cerca de Quito. El proyecto evita las fuertes pendientes del lugar y su unidad la consigue mediante la adicion horizontal de las dependencias requeridas por el programa dispuestas paralelas y con vistas al valle. Para ello recorta el pefil de la ladera configurando una platea sobre la que desplegar la planta ideada; se trata de 8 dependencias recorridas por un corredor paralelo a la vereda de ingreso. La materialidad de este pasillo es la piedra del lugar y la madera cortada "enbuena 


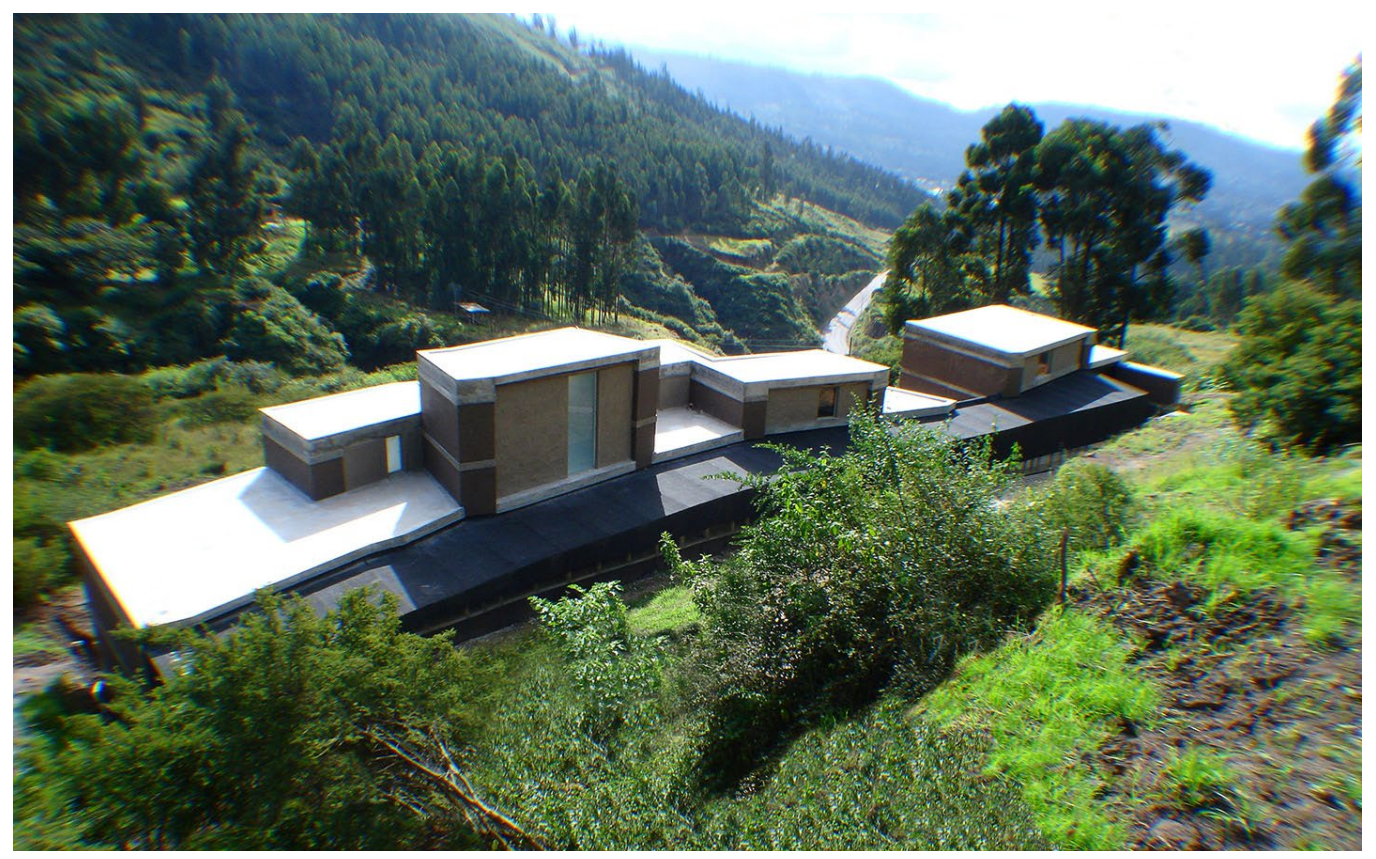

Figura 05.

Casa Entremuros. Tumbaco. Ecuador. Arqs. Al borde. 2008. Fotografía Al borde.

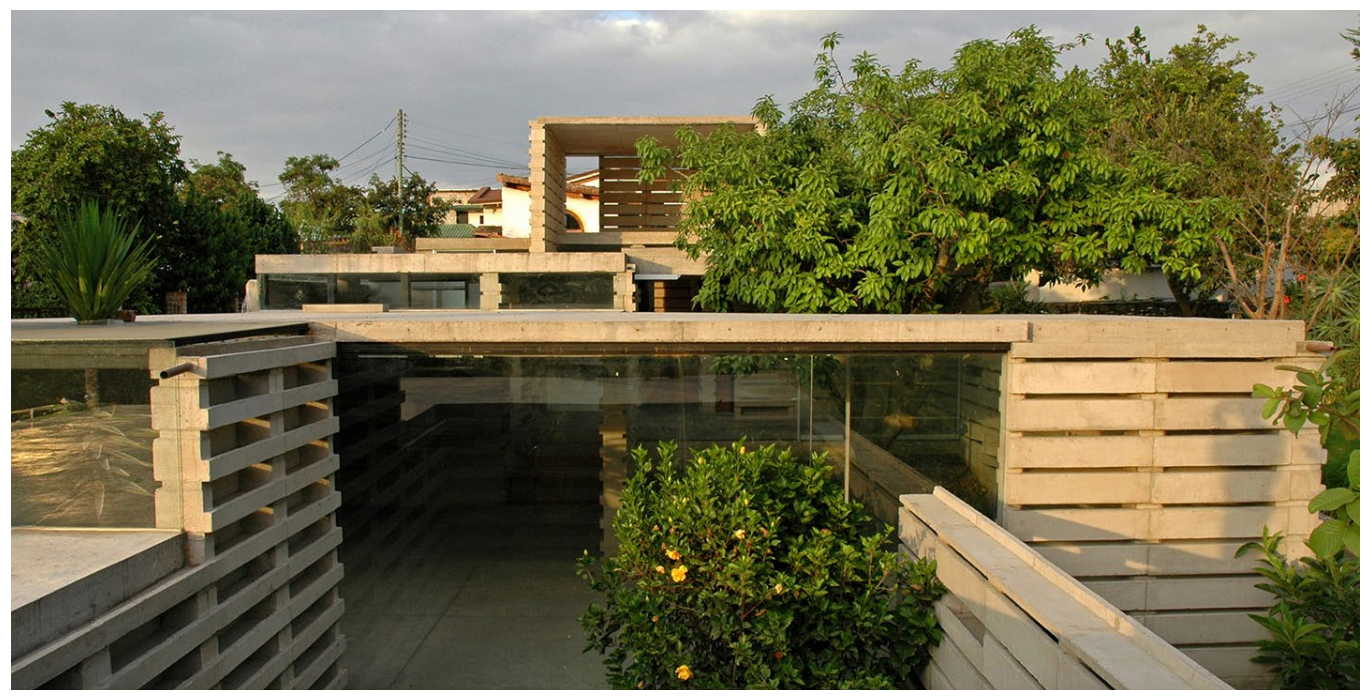

Figura 06.

Casa Partimento. Quito. Ecuador. Arqs. José M. Vaquero - David Barragán. 2006. Fotografía Al borde. 


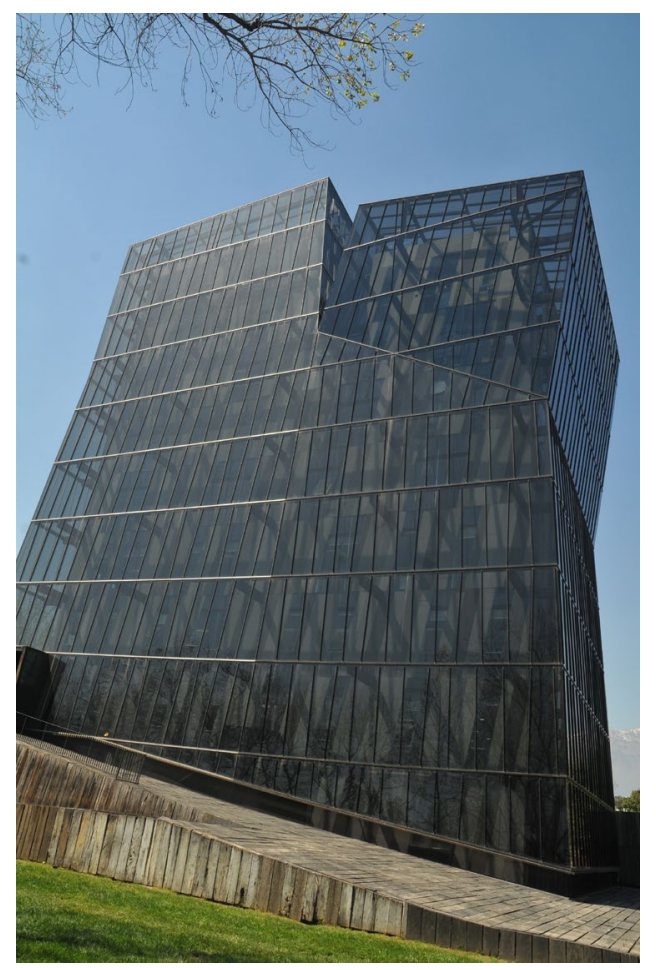

Figura 07.

Torres Siamesas, Campus San Joaquín, Universidad Católica de Chile. Santiago .Arq. Alejandro Aravena. 2005. Fotografía Emilio Farruggia luna" sin maquinar, usada como columna y como cieloraso.

Las habitaciones se delimitan mediante gruesos muros portantes construidos con tierra consolidada obtenida del recorte del terreno. El desarrollo verical de esas tapias se modula para incluir unas losas de hormigon que sirven a estabilizarlas. Los muros así construidos son 10 y no se los hace paralelos para evitar el efecto dominó. Los argumentos de sus autores refieren a economizar utilizando mayormente material del lugar, como la tierra y la madera, saludable, no contaminante y sustentable. A la vez los volumenes adicionados, sus variaciones en altura, la horizontalidad, el color resultante, instalan una arquitectura que al decir de sus autores "busca poner en evidencia la naturaleza material de los elementos que lo componen, potenciando sus cualidades estéticas, formales, estructurales y funcionales".

Cuando la Universidad Catolica de Santiago le propuso al arquitecto Alejandro Aravena construir un edificio con su envolvente de vidrio, de varias plantas, destinado a alojar los medios informaticos con los que cuenta la institucion en el campus San Joaquin, los proyectistas debieron atender varios problemas: las cualidades del vidrio, las áreas de trabajo y las limitaciones presupuestarias. Estas condiciones crearon el problema material y formal del edificio para lo cual se imaginó un ingenioso proyecto. 


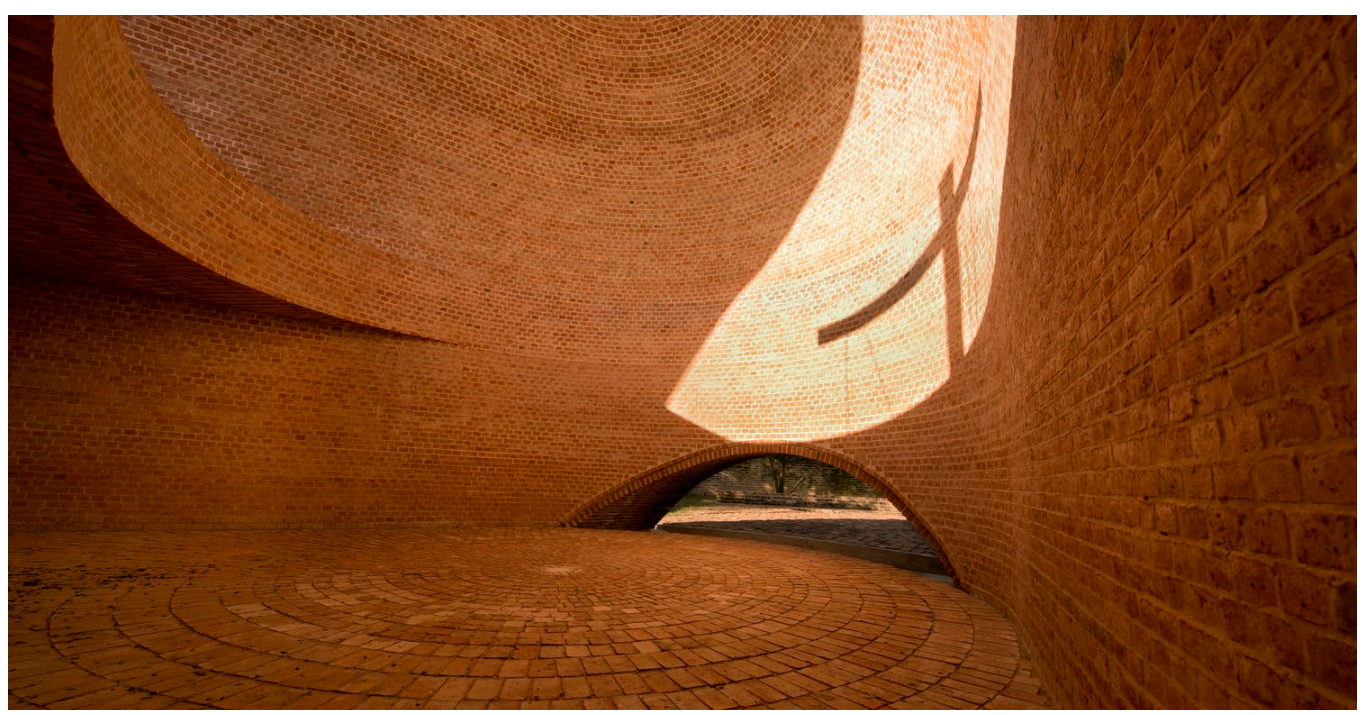

Figura 08.

Capilla San Bernardo. Pcia. De Córdoba. Arq. Nicolás Campodónico. 2015. Fotografía N. Campodónico.

El proyectista dudó fuertemente de la eficacia formal de las proporciones del edificio resultante segùn los compomisos programáticos. En su lugar optó por devidir los pisos superiores en dos alas y alterar las verticales. El proyecto del edficio sigue la logica constructiva de las construcciones en seco, y por lo tanto, diferencia el cierre exterior del interior,estableciendo para cada una, una materialidad acorde a su función: el vidrio simple, económicamente accesible resuelve la primera capa, la externa, la que no toca el piso, previen la lluvia y el polvo, regula la luz, pero no controla la temperatura interior. El fibrocemento atiende el cerramiento interior, conforma la segunda capa separada del vidriado, con la que se protege las cualidades amibientales interiores. Esta separacion introduce el tercer material, el aire, y a modo de chimenea facilita el ascenso de las corrientes calientes tras el vidrio. Las envolventes de fibrocemento apenas perforadas buscan generar una iluminacion intencionadamente regulada y apropiada a la utilizacion de las pantallas de los monitores.

Capilla San Bernardo. Zona Rural. Provincia de Córdoba. Arq. Nicolás Campodónico.

Una pequeña obra pero de alto valor emocional es la capilla dedicada a San Bernardo que el arquitecto Nicolás Campodónico realizó en la zona rural de la Piayosa, en la Provincia de Córdoba, lugar alejado y de escasos recursos materiales y técnicos. La obra fue seleccionada y finalista de la bienal de San Pablo del año 2016. 
Su aspecto exterior no denota que se trata de un edificio religioso, y tampoco coincide con el diseño de su espacio interior. Si por fuera se presenta como una volumetría de fuertes aristas rectas, recortada en su lado oeste mediante una cara oblicua que capta el movimiento de la luz que produce la rotación de la tierra, su interior se configura con las curvas de un techo abovedado, también parcial, para abarcar el ingreso de la luz solar durante la tarde.

El recinto no cuenta con ningún elemento propio del equipamiento religioso, e invita más a la reflexión que al rito. No tiene altar, ni atrio, y su cruz, no es material, sino una sombra que se compone a cierta hora de la tarde cuando los dos maderos, uno vertical y otro horizontal, puestos separados en la abertura proyectan su sombra conjunta sobre uno de los muros que conforman el cierre interior.

Toda la obra es de ladrillo, buena parte de los cuales fueron recuperados de las demoliciones anteriores realizadas en el campo. El pequeño edificio se instala dentro de un recinto delimitado por una secuencia de paredes que a modo de patio delimitan su exterior dentro de la extensa llanura pampeana. Las bóvedas fueron construidas según una ingeniería no habitual que evitó la cimbra y aceptando el riesgo de derrumbes. Seguramente su destino religioso encuentra en la austeridad de su proyecto y construcción la respuesta más apropiada. Sin embargo debe resaltarse además, el compromiso formal y tectónico que la obra asume y responde de modo altamente satisfactorio.

\section{CONCLUYENDO}

Los proyectos de las obras descriptas adquieren riqueza, esto es valor y suman complejidad en tanto, como se ha tratado de mostrar, la materia no es inerte, o simple consecuencia; en esos casos se establece en el lugar de la reflexión que desplaza la centralidad de la forma visual. Desde nuestro punto de vista esta es la situación que nos parece más meritoria de estas arquitecturas relevantes de la actualidad sudamericana: salir de la especulación de la forma visual, y pasar a las expectativas de la recepción conceptual y sensorial.

Cuando Florencia Garamuño analiza la obra de Nuño Ramos, caracterizada por instalaciones que combinan distintos materiales y medios artisticos, enuncia conceptos que ilustran nuestras observaiones relacionadas con el interés de los arquitectos incluidos por alejarse de los lenguajes formales y, en su lugar, procurar otras configuraciones sensibles. Dice Florencia Garramuño:

La disposición de materiales y los medios en el espacio lleva al espectador a considerar los efectos y enigmas que esta disposición produce, en vez de centrarse en la forma estética. Al retirar el arte de la forma y acercarlo a los efectos sensoriales que emanan de esta disposición, la consideración 


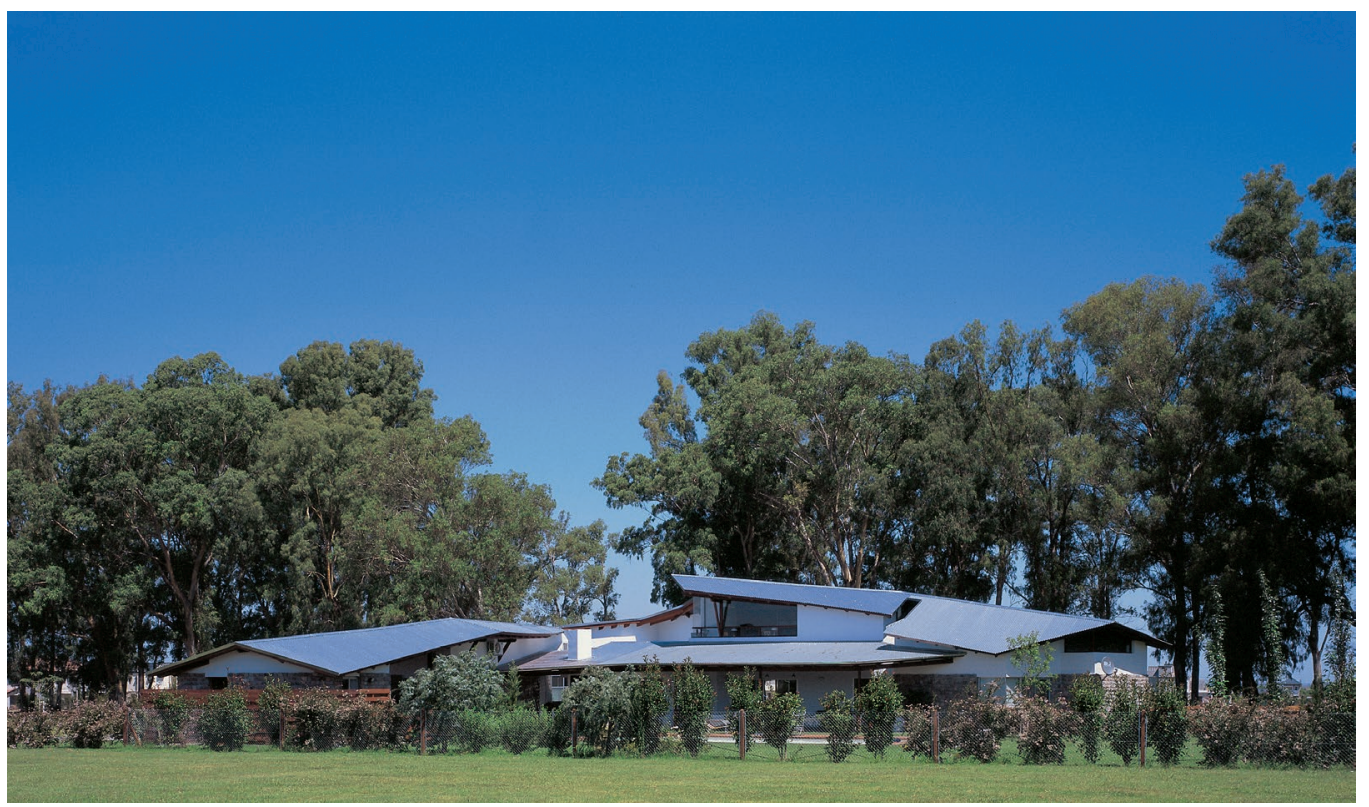

Figura 09.

Casa Brown. Arq. Marcelo Villafañe. Funes. Argentina. 2007. Fotografía Marcelo Villafañe.

de los efectos y de las relaciones entre los objetos y materiales adquiere mayor importancia en la recepción de esta práctica estética.

(Garramuño,2015,p172)

De este modo la autora aventura una mayor precisión al vincular el desplazamiento desde la valoración de la forma hacia los efectos sensoriales que surgen de la disposición de los materiales, y en nuestro caso, en la propia configuración del edificio y sus espacios.

La arquitectura, en versiones críticas, ha dejado de ser objeto referenciado. Tampoco la entendemos como reflejo o expresión de sentidos ocultos y no da evidencias de corrientes globales en las que se arraigan; en todo caso, cuentan de un mundo en el que tanbien circulan corrientes que se oponen a las fuerzas globalizadas con afán de hegemonizar. Las desviaciones hacia procedimientos imaginativos no habituales son parte de la intensa proliferación de las más diversas manifestaciones artísticas y muestran sus alcances en el ejercicio de la arquitectura. Como hemos dicho más arriba, las entendemos como múltiples acontecimientos disperos que forman parte de un mosaico ilimitado y global. Es lo que vemos cuando Smiljan Radic incorpora la escultura en sus obras, analogías con la escenografía y ciertas metáforas que le ayudan a componer los relatos de sus proyectos. También cuando Rafael Iglesia reitera sus conexiones 
con la literatura de Jorge Luis Borges, y verificamos la atención que puso también en la metáfora y en cierta lógica de lo primitivo, originario, relacionada a la experimentación. Lo verificamos en la trayectoria de Marcelo Villafañe cuando en silencio piensa pintura y arquitectura. Finalmente cuando Solano Benítez vincula la investigación material con el compromiso de inventar los modos de salir de las cosas "bien realizadas".

Florencia Garramuño diría que estas operaciones representan "alteraciones de la estética contemporánea” y en ambos caso "propician modos de organización de lo sensible que ponen en crisis ideas de pertenencia, especificad y de autonomía". Parece estar presente todos los indicios del desplazamiento hacia lo inespecífico e impropio. "No se sabe bien qué es" dice Iglesia y es cierto, y por su condición urbana, el frente de la clínica se asimila más a una instalación que a una obra de arquitectura, en la que el reflejo distorsionado de las fachadas de enfrente cambia según las horas del día y el recorrido del caminante. En el caso del restaurante Radic las enormes piedras de granito y el hormigón visto construyen el significado, se ocupan de la dimensión subjetiva, el imaginario, que trasciende la finalidad.

\section{Esa transformación de valores que reconocemos} sucede en el ámbito sudamericano no se presentan a modo de teorías y manifiestos que confrontan con un orden que debiera ser olvidado y superado, o dicho de otra manera, no son opciones confrontativas al modo moderno, es decir, no surgen como contra cultura. Sus autores se sienten parte de este mundo que los ha destacado y puesto en valor y a la vez que se involucran, son críticos, y buscan distancianciarse de las reducciones funcionalistas, utilitarias, el pragmatismo, la pereza intelectual. No obstante, queremos decir que estas arquitecturas no predominan y son expresiones menores dentro de un contexto pragamático, profesionalizado según los requisitos necesarios de las corporaciones tanto productivas como formativas. Sin embargo esta disciplina da muestra constantes, de ser partícipe de los actividades y movimientos artísticos que circulan en los tiempos en los que se desenvuelve, por los que ve afectada por sus reflexiones y producciones, sin que por ello pierda su finalidad práctica, útl y necesaria. Sus rasgos artísticos se muestran cuando en lugar de pensar en nuevas estéticas derivadas de nuevas formalizaciones y la presentación de nuevas tendencias, como sucedió en otros momentos, piensan en otros procedimientos, otras sensibilidades y otros relatos. Finalmente, estas producciones más que suponerse con el romanticismo de una vanguardia que imagina una sociedad transformada por la arquitectura, prefieren ubicarse obstinadamente en los márgenes de la producción artística de una profesión que la evita. 


\section{BIBLIOGRAFÍA}

AIRA, C.(2013). Sobre el arte contemporáneo. Buenos Aires. Randon House Grupo Editorial.

ADORNO, T. (1970). Teoría Estética. Buenos Aires. Hipamerica Ediciones.

ARGÁN, G. (1973). El concepto del espacio Arquitectónico. Buenos Aires. Nueva Visión.

BOUDRILLARD, J. (2000). Los objetos singulares. Ed. Fondo de Cultura Economica.

BERTONI, G. (2012). Forma y Materia. Un mapa de la arquitectura latinoamericana contemporánea. Santa Fe. Ediciones UNL.

CORONA MARTÍNEZ, A. (1998). Ensayo sobre el Proyecto. Editorial CP67. Buenos Aires.

DE SOLÁ - MORALES, I. (1990). Diferencias. Topografía de la arquitectura contemporánea. Barcelona. Ed. Gustavo Gilli.

DELEUZE, G. (1989). El Pliegue. Paris. Ed. Paidos Iberica.

FERNÁNDEZ, R. (2004). Lógicas del Proyecto. Buenos Aires. Ed. FADU-UBA.

FERNANDEZ, R. (2007). Teoría del Proyecto Americano. Seminario. Bolivia.

FERNÁNDEZ, R. (2013). Inteligencia Proyectual. Un manual de investigación en arquitectura. Buenos Aires. Ed. Teseo.

FRAMPTON, K. (1990). El regionalismo crítico: arquitectura moderna e identidad cultural en
Historia Crítica de la arquitectura moderna. Ed. Gustavo Gilli.

FRAMPTON, K. (1999). Estudios sobre la cultura tectónica. Madrid. Gustavo Gilli.

GARRAMUÑO, F. (2015). Mundos en común. Ensayos sobre la inespecificidad en el arte. Buenos Aires. Ed. Fondo de Cultura Económica.

GAUSA, M. y DEVESA, R. (2010). Otra Mirada. Posiciones contra crónicas. Barcelona. Ed. Gustavo Gilli.

GUTIÉRREZ, R. (1997). Arquitectura y Urbanismo en Iberoamérica. Ediciones Cátedra. Madrid.

HUYSSEN, A. (1986). Después de la gran división. Buenos Aires. Adriana Hidalgo editora S.A. Buenos Aires.

LIERNUR, J. (2010). Arquitectura, en teoría. Buenos Aires. Nobuko.

MONTANER, J. (2002). Las formas del siglo XX Madrid. Ed. Gustavo Gilli.

MONTANER, J. (2011). Arquitectura y crítica en Latinoamérica. Buenos Aires. Ed. Nobuko.

PALLASMAA, J (2012). La mano que piensa. Sabiduría existencial corporal en la Arquitectura. Madrid. Ed. Gustavo Gilli.

Piñon, H. (2005). Materiales del proyecto. Barcelona. Escuela Técnica Superior de Arquitectura. Barcelona. 
QUETGLAS, J. (1999). Pasado en limpio II. Barcelona. Ed. Pre-Textos. Colegi d'Arquitects de Catalunya.

RIGOTTI, A. y PAMPINELLA, S. (2009). Una cosa de Vanguardia. Rosario. A\&P ediciones. UNR.

ROWE, C. (1978). La estructura de Chicago en Manierismo y arquitectura moderna. Barcelona. Ed. Gustavo Gilli.

SENNETT, R. (2008). El artesano. New Haven. Ed. Anagrama.

SMITH, T. (2009). Qué es el arte moderno. Buenos Aires. Ed. Siglo XXI.

WANG, W. (2009). The O'Neil Ford Duograph Series. Center for American Architecture Design. The University of Texas of Austin.

VATTIMO, G. (1989). La sociedad Transparente. Ediciones Paidos Iberica S.A. Barcelona.

ZUMTHOR, P. (2014). Pensar la Arquirtectura. Basilea. Ed. Gustavo Gilli. 